\title{
Shear and Hardness Properties Study of AA-6061 Aluminium Alloy Lap- Joints Produced by Friction Stir Spot Welding Process Using H13 Tool Steel
}

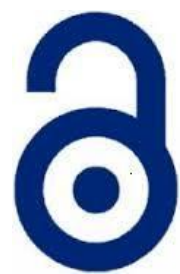 \\ Received: 12 March 2021 \\ Accepted: 08 May 2021 \\ Published: 15 July 2021 \\ Publisher: Deer Hill Publications \\ (c) 2021 The Author(s) \\ Creative Commons: CC BY 4.0
}

Afif bin Mohamad Hanapiah, Sumaiya Islam, Neamul Khandoker and Abdul Md Mazid

\begin{abstract}
By virtue of high-strength verses weight ratio aluminium alloys are achieving attentions in automobile, marine, and aircraft industries as it reduces the fuel consumption for running the vehicles. But their main drawback is the destruction of their carefully engineered microstructures by high heat generated in traditional welding processes. Friction Stir Welding (FSW) minimizes excessive heat in the welding zone and does not influence the microstructural features. FSW is currently one of the recommended solutions for manufacturing aluminium alloy welded machine parts. In this study, AA6061 Al-alloy strips were lap joined using the improvised FSW setup tool clamping it on the spindle of a CNC milling machine with the speed rate varied from $1000 \mathrm{rpm}$ to $3000 \mathrm{rpm}$, and three different feed rates 5,15 , and $25 \mathrm{~mm} / \mathrm{min}$. Shear strength experiments of these joints revealed that samples created with the speed rate of $1000 \mathrm{rpm}$ and feed rate of $25 \mathrm{~mm} / \mathrm{min}$ performed best showing the highest load carrying capacity of $8976 \mathrm{~N}$ with elongation of $1.04 \%$. They also demonstrated highest Vickers hardness value of 31 at the centre of the weldment. Keywords: 6061 Aluminium alloy, machine design, friction stir welding, shear strength, hardness, automobile
\end{abstract}

\section{INTRODUCTION}

Friction Stir Welding (FSW) is based on a very simple concept. In 1991, The Welding Institute (TWI), UK invented friction stir welding in which a rotating pin stirs the material across the joint line forming the bond with two plates of either same or dissimilar material. The friction between the tool and the top surface of material will generate heat and cause plastic deformation of the material without melting it [1]. The FSW process takes place in the solid phase below melting temperature point of the material. As a result, it does not experience defects related to re-solidification, porosity, and cracking. The joint will have a fine microstructure and lead to good mechanical properties compare to usual fusion welding technique which causes degradation to weld material [1]. Furthermore, lower temperature operation will reduce distortion and residual stresses.

Figure 1 shows the process of Friction Stir Spot Welding (FSSW) to a lap joint with two sheets. A rotating tool with the pin is plunged into the material from the top surface of the upper sheet for given time to generate heat from the friction and plastic deformation. There is a backing plate to support the lower sheet from downward tool force. Softened material near the tool cause plastic flow and the mix up of upper and lower sheets materials with assistance from the shoulder that provides compressive force. The solid phase bond is built after the tool is drawn away from the material. The appearance and cross-sectional configuration of spot stir welding shown in Figure 2. The top surface will look like a button with hole and bottom surface is flat. From cross section it is observed that the upper and lower sheet materials are mixed, and the tool penetrates up to the lower sheet.

Previous studies demonstrated the effect of welding parameters on microstructure of DP600 steel material [3]. Formation of Bainite and Ferrites were discussed relating to the increased hardness property compared to the base metal. Another study used a mathematical model to predict the tensile strength of friction stir welded Aluminium alloy [4]. The developed model could predict the tensile strength of FSW joint with $95 \%$ confidence level. Studies of friction stir welding of dissimilar materials were also reported [5]. Apart from these there are a lot of information on friction stir welding process automation and control [6]. Self-optimization and tool wear of FSW process were also of importance for various researchers [7]. The objective of this current study is to develop a friction stir spot welding setup and use it to investigate the effect of FSSW process parameters on strength properties of the manufactured joints.

M.H. Afif', Sumaiya Islam¹, Neamul Khandoker²凶, Abdul Md Mazid² $₫$

'Department of Mechanical Engineering, Faculty of Engineering and Science, Curtin University, Malaysia.

${ }^{2}$ College of Engineering and Aviation, Central Queensland University, Melbourne, Australia.

E-mail: n.khandoker@cqu.edu.au \& a.mazid@cqu.edu.au 


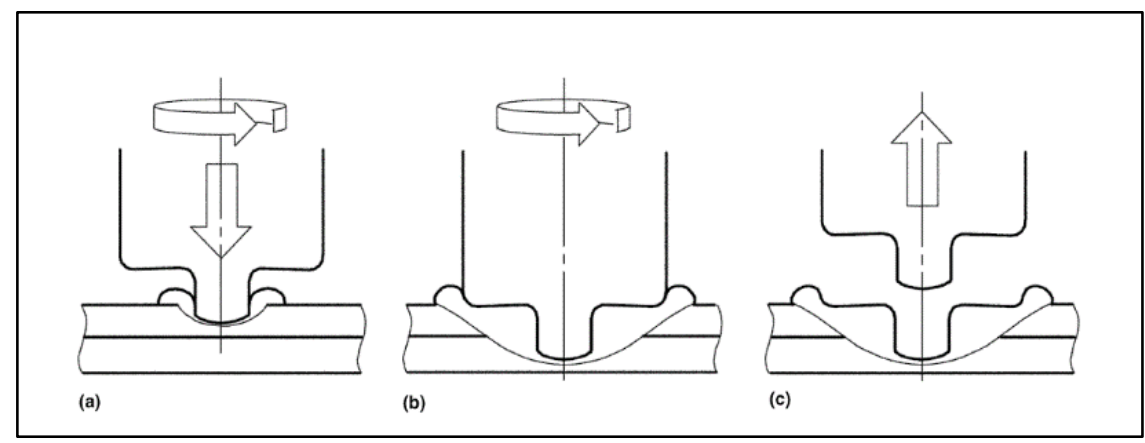

Figure 1: Friction Stir Spot Welding (FSSW) illustration. (a) Plunging state (b) Spot welding stage (c) Retraction stage [2]

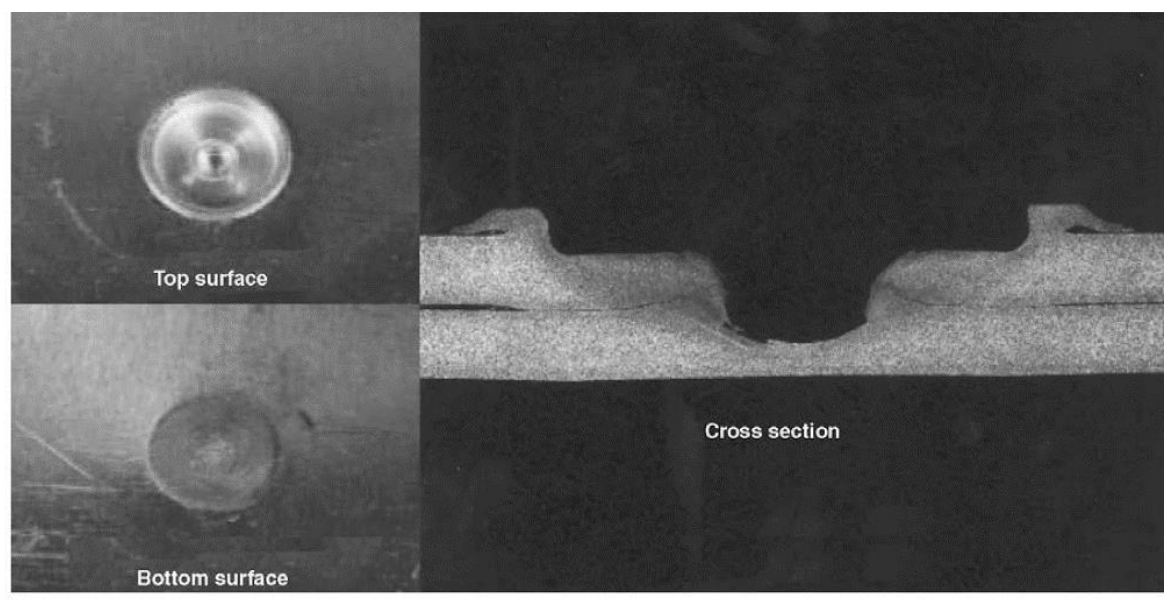

Figure 2: Spot friction stir welding appearance and cross section (Mishra, 2007)

\section{EXPERIMENTAL SETUPS \\ 2.1 Fixture and Backing Plate}

For friction stir spot welding, the design of backing plate and fixtures is crucial for weld quality. It is important that workpiece does not lift or move during the welding process. The objective of the design is to ensure that it provides good weld quality. Manufacturing of clamping system and welding table will determine the quality of the welding (Daniela Lowasser 2009). Fixture design contains several parts with different materials. First part is a backing plate which is placed below the weld specimen. It provides support for the axial force from the tool during the welding process. Also, the backing plate is required to withstand high-temperature operational environment and to have good heat dissipation properties to improve weld quality (P. Upadhyay 2010). Selected material for the backing plate is $\mathrm{H} 13$ tool steel. Tool steel was selected because of its excellent combination of resistance to thermal fatigue cracking and high toughness (Hudson Tool Steel Corporation 2016).

Next fixture component is the side plates. Weld coupon sides need to be supported against the rotational force from rotating tool. The elongated holes for the side plates are used to accommodate different sizes of the coupons. These plates do not require to have same properties as the baking plate and top plate because it has small contact area with the coupons. Last part is the top plate which provides clamping to the weld specimen in lap joint configuration. The clamp is needed to avoid unnecessary material distortion during applied force and arising temperatures. Selected material for this application is tool steel. For the tool, a simple design with high effectiveness is selected. In FSSW, the tool is the key component in generating required heat to soften the material for welding process and provide force to join two sheets together. Tool material must resist thermal fatigue cracking as it operates in high temperature. $\mathrm{H} 13$ Tool Steel was selected because of its combination of resistance to thermal cracking and toughness (AZOM 2013). H13 tool steel has been tested for many friction spot stir welding applications and gave better quality for pin less tool design (R Rai 2013). Table 1 show the chemical composition of the H13 tool steel. The complete FSSW manufacturing set-up is shown in Figure $-3,4$, and 5. 
Table 1: Chemical composition of $\mathrm{H} 13$ tool steel [8]

\begin{tabular}{ccccccc}
\hline Material & $\mathrm{C}$ & $\mathrm{Mn}$ & $\mathrm{Si}$ & $\mathrm{Cr}$ & Mo & $\mathrm{V}$ \\
\hline H13 Tool Steel & $0.32-0.45$ & $0.20-0.50$ & $0.80-1.20$ & $4.75-5.50$ & $1.10-1.75$ & $0.80-1.20$ \\
\hline
\end{tabular}

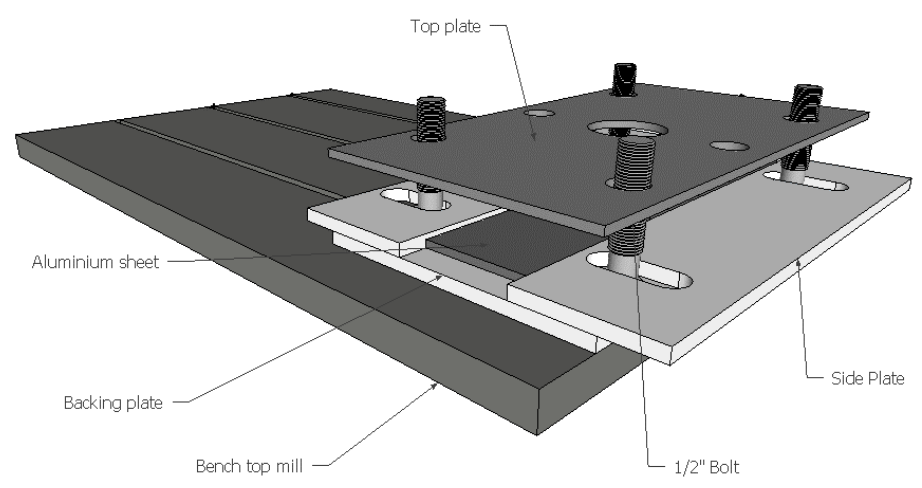

Figure 3: Friction stir spot weld manufacturing set-up

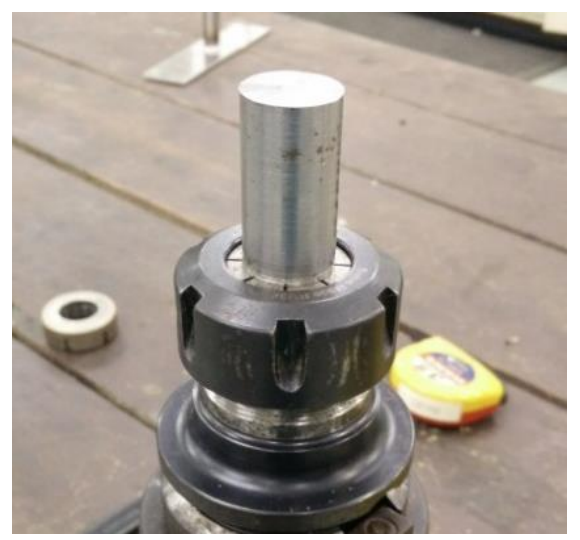

Figure 4: Tool fitted into collet and chuck

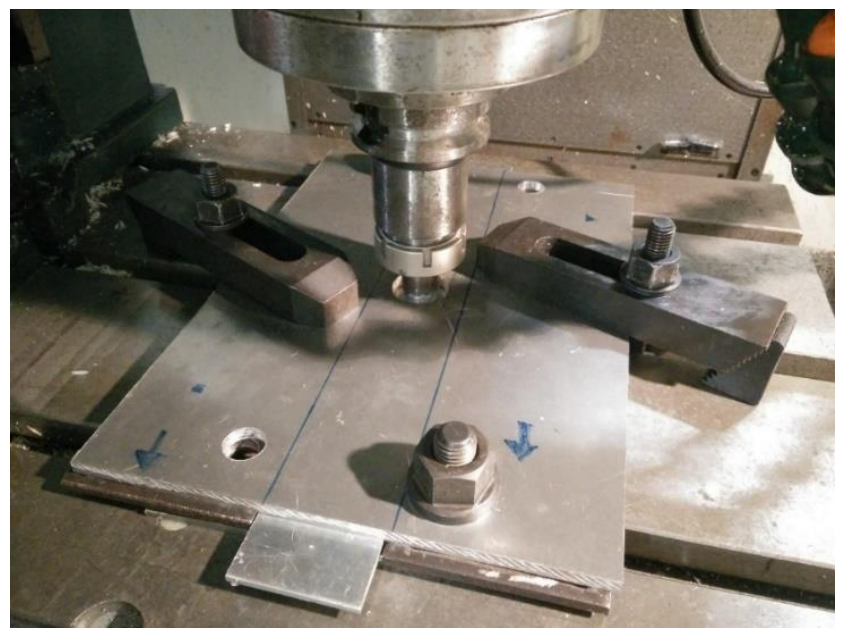

Figure 5: Assembly of FSSW fixture on the milling table 


\subsection{Welding Schedules}

The experiment was conducted according to the welding schedules below so that each weld condition has unique parametric setup. The FSSW capability window has been developed based on the rotational speed and feed rate of the tool of a CNC milling machine (LEADWELL V30). Pre-trial of the welding have been conducted to determine the maximum and minimum capacity of the CNC milling machine. The operational window of friction spot stir welding is shown in Table 2 and Figure 6. The experiment was conducted at each end of operation boundary and a point in the middle. The tool penetration depth was kept constant for all experiments at $4 \mathrm{~mm}$.

Table 2: Weld conditions for FSSW

\begin{tabular}{ccc}
\hline Condition & Tool rotation $(\mathrm{rpm})$ & Feed rate $(\mathrm{mm} / \mathrm{min})$ \\
\hline 1 & 3000 & 25 \\
2 & 3000 & 5 \\
3 & 2000 & 15 \\
4 & 1000 & 5 \\
5 & 1000 & 25 \\
\hline
\end{tabular}

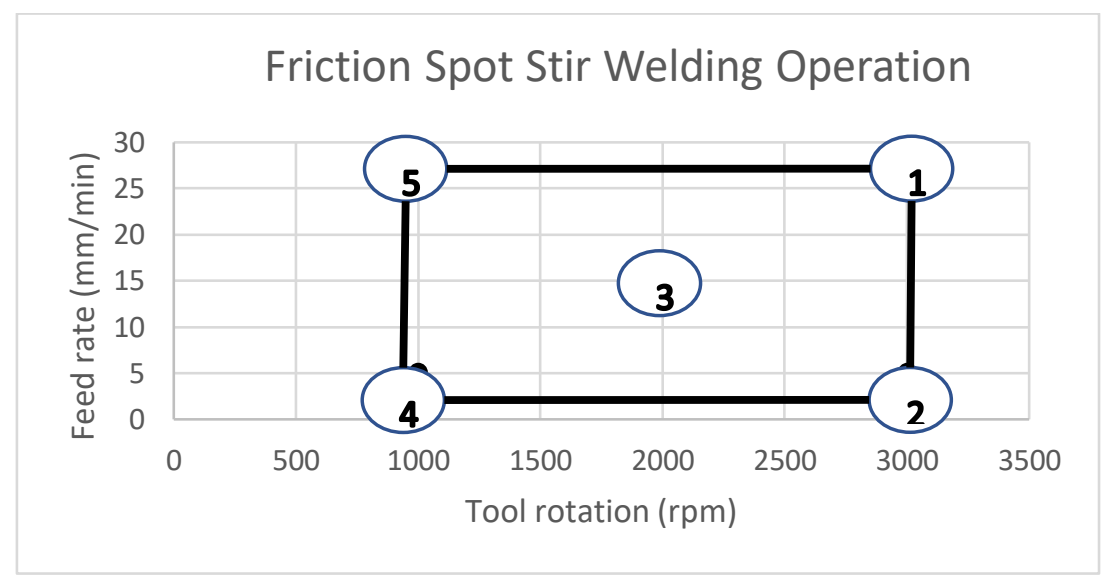

Figure 6: FSSW operational ranges

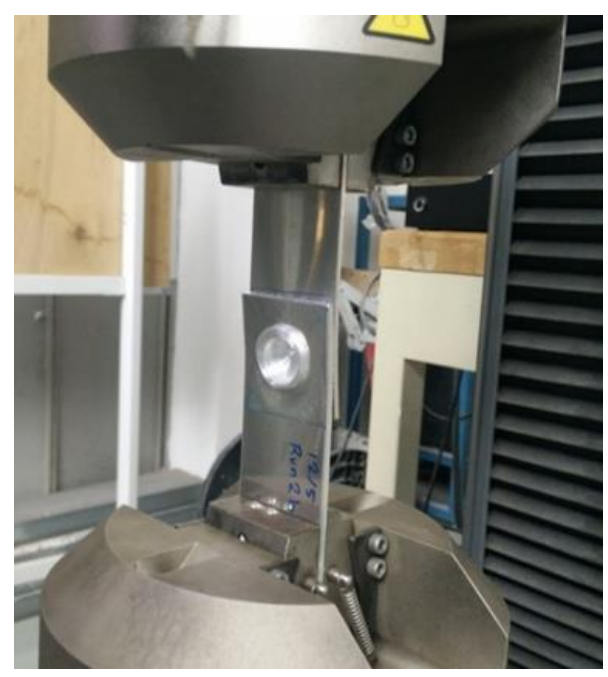

Figure 7: Weld coupon under lap shear tensile test with universal testing machine 


\section{RESULT AND DISCUSSION}

3.1 FSSW Lap Shear Strength

To investigate the quality of the friction spot stir welds manufactured at different conditions, samples from each weld conditions 1, 2, 3, 4, and 5 were tested for their strengths. The lap shear tensile tests were conducted with INSTRON 5982 universal testing machine. The samples were clamped to the machine as shown in Figure 7. As the test started, weld sample was pulled at a rate of $1 \mathrm{~mm} / \mathrm{min}$. All the data was recorded in a computer connected to the testing machine using Instron Bluehill software.

Based on the graph in Figure 8, weld produced under condition 5 (1000 rpm, and $25 \mathrm{~mm} / \mathrm{min}$ feed rate) had the highest average strength of $8976 \mathrm{~N}$ followed by condition $4(1000 \mathrm{rpm}$, and $5 \mathrm{~mm} / \mathrm{min}$ feed rate) with around $7600 \mathrm{~N}$ strength. Lowest strength was obtained by condition $3(2000 \mathrm{rpm}$, and $15 \mathrm{~mm} / \mathrm{min}$ feed rate) followed by condition 1 (3000 rpm, and $25 \mathrm{~mm} / \mathrm{min}$ feed rate) and condition 2 (3000 rpm, and $5 \mathrm{~mm} / \mathrm{min}$ feed rate). Condition 5 shows that slow tool speed combined with high feed rate resulted into strong lap shear strength as the material around the tool properly stirred and mixed with combinations of high axial pressure. Moreover, high tool speed caused larger grain size of the microstructure resulting into a reduction of weld strength [9].

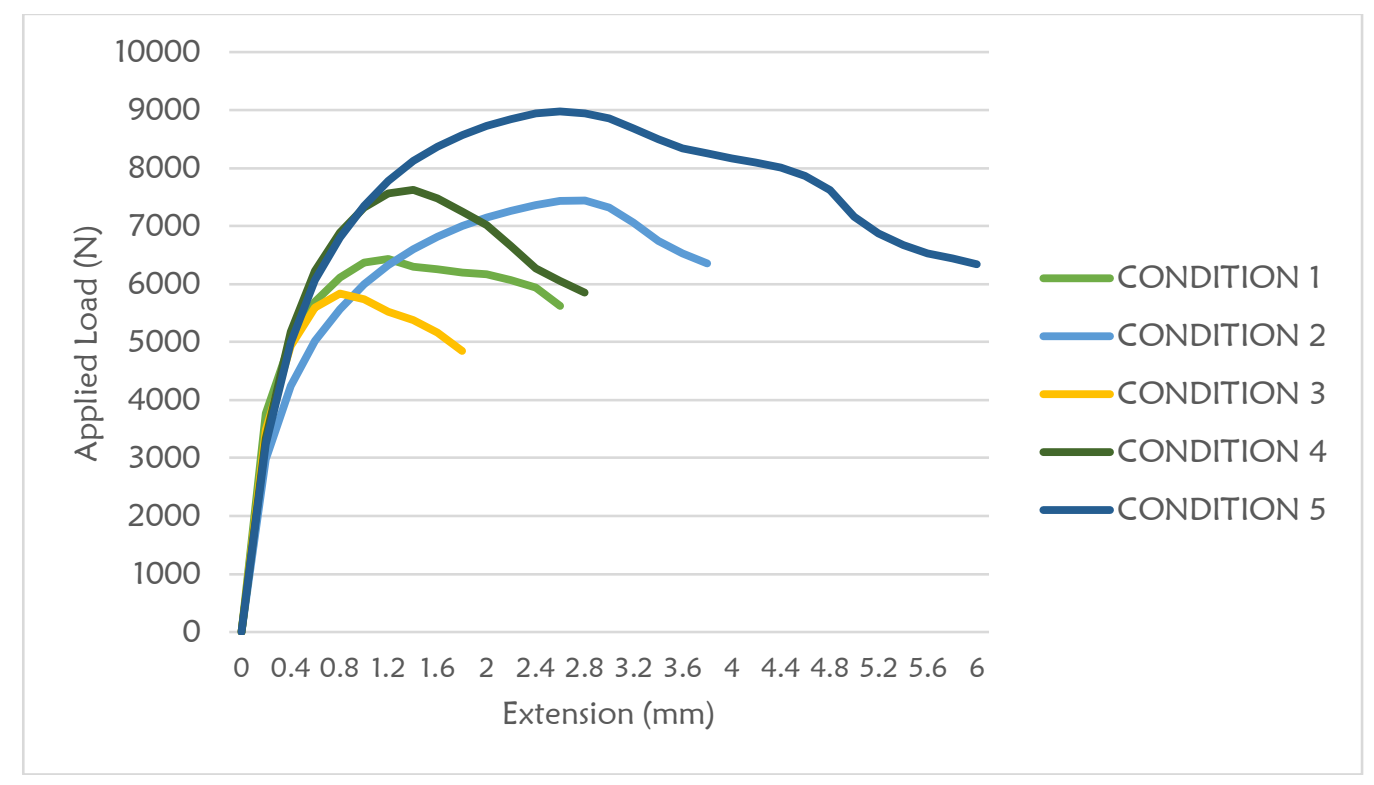

Figure 8: Graph of load vs extension (compared all condition)

\subsection{Lap Shear Strength Optimization}

From experimentally obtained shear strength data, further analysis has been made to determine the optimization point for welding process parameters such as feed rate and tool speed. Data optimization of the welding process was determined using Design Expert ${ }^{\circledR}$ Software. For this experiment, the welding parameters were limited to an operational range determined earlier as shown in Figure 6. The output of the software is shown in Figure 9. For optimum design point equal to one, the parameter is outside the operational boundary. Therefore, the best prediction is close to experimental condition 5 (1000 rpm, and $25 \mathrm{~mm} / \mathrm{min}$ feed rate) with a design point of 0.825 . 


Design-Expert@ Software
Factor Coding: Actual
Desirability
o Design Points
目 1.000
0.000
X1 = A: RPM
X2 $=$ B: Feed

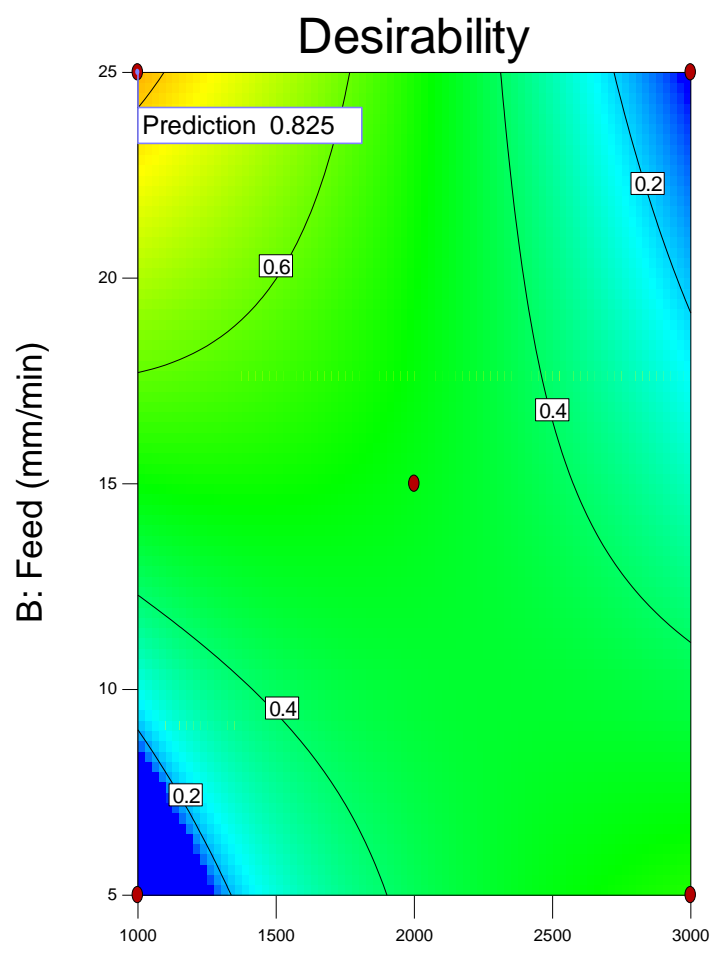

A: RPM (rpm)

Figure 9: Desire points for optimized welding parameter

\subsection{Hardness Distribution}

Figure 10 shows the position of the hardness profile test for welded aluminium. The tests were conducted based on ATSM E92-2016 standard [10]. Samples were tested across the weld area using AKASHI Vickers Hardness Tester. Three points were selected for each sample. One point at the centre of tool insertion and one point at the left side and another at right side with $7 \mathrm{~mm}$ distance apart. One kg indentation force for 10 seconds was used for all the tests.

Figure 11 shows the hardness profile for all weld conditions. It was observed that all manufacturing conditions produced almost the same hardness trend. Hardness is at its peak in position 2 which is the centre of the weld and the hardness value decrease towards the outer diameter of the weld.

It is also can be observed that condition 5 (1000 rpm, and $25 \mathrm{~mm} / \mathrm{min}$ feed rate) had the highest overall hardness followed by condition 4 (1000 rpm, and $5 \mathrm{~mm} / \mathrm{min}$ feed rate). Lowest overall hardness was observed for condition 1 (3000 rpm, and $25 \mathrm{~mm} / \mathrm{min}$ feed rate). It shows that feed rate has a minor influence on the obtained hardness values.

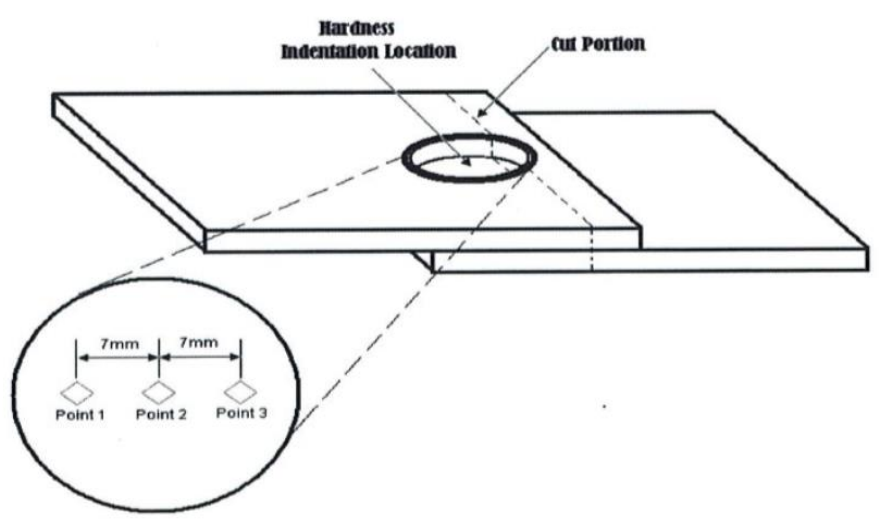

Figure 10: Hardness profile measurement positions 


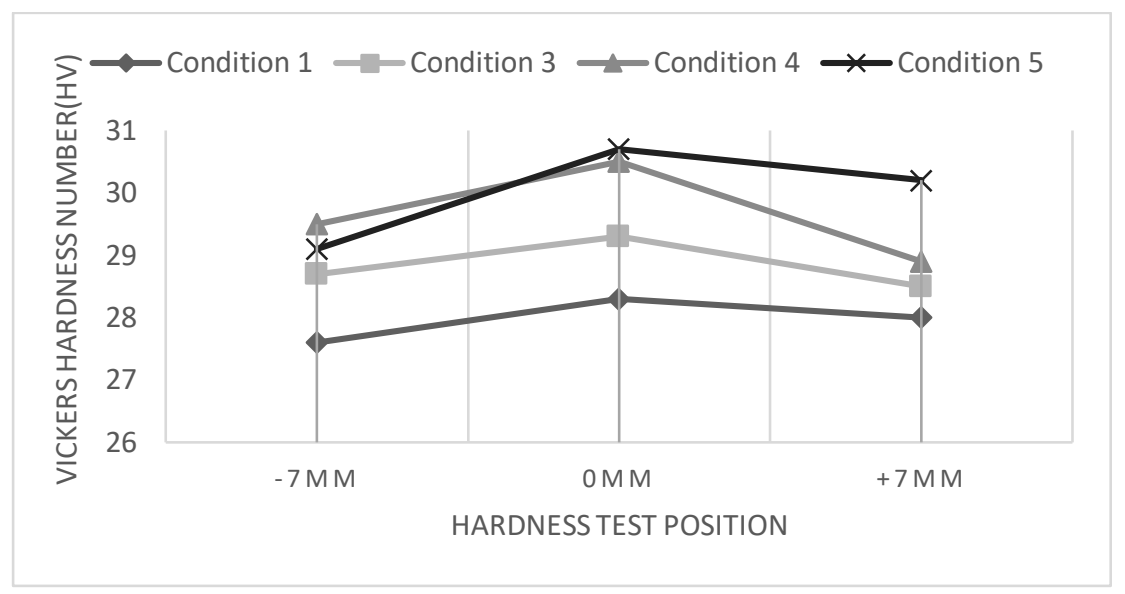

Figure 11: Hardness profile for FSSW Aluminium

\section{CONCLUSIONS}

The aim of this study was to gain a better understanding of the friction stir spot welding process so that it can be an alternative to conventional lap joining processes. By using a CNC milling machine, friction spot stir welding was performed successfully. The key components for friction spot stir welding for Aluminium are the tool and a good fixture. There were three components of the fixture used in the experiment which were a backing plate, side plates and top plate. All components functioned as per the design. Following is the summary of obtained results.

- The process of friction spot stir welding was achieved with the designed fixtures and good welds were manufactured.

- Friction stir spot weld quality was determined based on the lap shear strength and Vickers hardness number.

- The highest strength of $8976 \mathrm{~N}$ at $2.6 \mathrm{~mm}$ extension was obtained at the FSSW manufacturing condition of $1000 \mathrm{rpm}$ and $25 \mathrm{~mm} / \mathrm{min}$ feed rate.

- The highest Vickers Hardness values (HV) were obtained at the centre of each weld for all manufacturing conditions.

- The highest overall hardness number (HV 31) was obtained at $1000 \mathrm{rpm}$ and $25 \mathrm{~mm} / \mathrm{min}$ feed rate and the lowest overall hardness number (HV 28) was obtained at $3000 \mathrm{rpm}$, and $25 \mathrm{~mm} / \mathrm{min}$ feed rate.

\section{REFERENCES}

1. K. Mishra, Friction Stir Welding and Processing Science and Engineering, Springer, 2014.

2. M. W. M. Rajiv S. Mishra, Friction Stir Welding and Processing, ASM International, 2007.

3. Hamid Ashrafi, M Shamanian, R. Emadi, and M Ahl Sarmadi, "Effect of welding parameters on the microstructure and tensile properties of friction stir welded DP600 steel," SAE Int. J. Mater. Manuf., 2019.

4. K. Elangovan, V. Balasubramanian, S. Babu, "Predicting tensile strength of friction stir welded AA6061 aluminium alloy joints by a mathematical model," Materials and Design, 30, pp 188-193, 2009.

5. Sadeesh P, Venkatesh Kannan M, Rajkumar V, Avinash P, Arivazhagan N, Devendranath Ramkumar K, Narayanan S, "Studies on friction stir welding of AA 2024 and AA 6061 dissimilar metals," Procedia Engineering, 2014.

6. B.T. Gibson, D.H. Lammlein, T.J. Prater, W.R. Longhurst, C.D. Cox, M.C. Ballun, K.J. Dharmaraj, G.E. Cook, A.M. Strauss, "Friction stir welding: Process, automation, and control," Journal of Manufacturing Processes, 2014.

7. R.A. Prado, L.E. Murr, K.F. Soto, J.C. McClure, "Self-optimization in tool wear for friction-stir welding of Al 6061+20\% $\mathrm{Al}_{2} \mathrm{O}_{3}$ MMC, Materials Science and Engineering A, 349, pp 156-165, 2003.

8. AZoM, "H13 Tool Steel - Chromium Hot-Work Steels," 10 July 2013. [Online]. Available: http://www.azom.com/article.aspx?ArticlelD=9107. [Accessed 20 mac 2017].

9. Zhaohua Zhang, Xinqi Yang, Jialong Zhang, Guang Zhou, Xiaodong Xu, Binlian Zou, "Effect of welding parameters on microstructure and mechanical properties of friction stir spot welded 5052 aluminum alloy," Materials and Design, pp. 4461-4470, 2011.

10. ASTM E92 - 16, ASTM International, West Conshohocken, PA, 2016. 
11. Z. C. Daniela Lowasser, Friction Stir Welding: From Basics to Applications, Elsevier, 2009.

12. A. R. P. Upadhyay, "Effects of thermal boundary conditions in friction stir welded AA7050-T7 sheets," Materials Science and Engineering, p. 1537-1543, 2010.

13. "Hudson Tool Steel Corporation," 2016. [Online]. Available: http://www.hudsontoolsteel.com/technicaldata/steelH3. [Accessed 26 October 2016].

14. A. D. H. K. D. H. B. \&. T. D. R Rai, "Review: friction stir welding tools," Science and Technology of Welding and Joining, pp. 1743-2936, 2013.

15. A. B. Ashu Garg, "On lap shear strength of friction stir spot welded AA6061 alloy," Journal of Manufacturing Processes, pp. 203-215, 2017.

16. Y. J. Chao, "Failure mode of spot welds:interfacial versus pullout," Science and technology of welding and joining, pp. 133-137, 2003. 